\title{
Experimental and Kinetic Study on the Production of Furfural and HMF from Glucose
}

\author{
Ouwen He ${ }^{1}$, Yangfan Zhang ${ }^{1}$, Pan Wang ${ }^{2}$, Lina Liu ${ }^{1} * \mathbb{D}^{\mathbb{D}}$, Qian Wang ${ }^{1}$, Nan Yang ${ }^{1}$, Wenjie Li $^{3}$, \\ Pascale Champagne ${ }^{4}$ and Hongbing $\mathrm{Yu}^{1, *}$
}

1 College of Environmental Science and Engineering, Nankai University, 38 Tongyan Road, Jinnan District, Tianjin 300350, China; heouwen@mail.nankai.edu.cn (O.H.); zhangyf@mail.nankai.edu.cn (Y.Z.); 17oh1@queensu.ca (Q.W.); yangnan@nankai.edu.cn (N.Y.)

2 Key Laboratory of Cleaner Production and Integrated Resource Utilization of China National Light Industry, Beijing Technology and Business University, Beijing 100048, China; wangpan@th.btbu.edu.cn

3 School of Ecology and Environment, Zhengzhou University, Zhengzhou 450001, China; wenjieli@zzu.edu.cn

4 Department of Civil Engineering, Queen's University, Kingston, ON K7L 3N6, Canada; pascale.champagne@queensu.ca

* Correspondence: liuln@nankai.edu.cn (L.L.); yuhb@nankai.edu.cn (H.Y.); Tel.: +86-18526446994 (L.L.); +86-13920683244 (H.Y.)

check for updates

Citation: He, O.; Zhang, Y.; Wang, P.; Liu, L.; Wang, Q.; Yang, N.; Li, W.; Champagne, P.; Yu, H. Experimental and Kinetic Study on the Production of Furfural and HMF from Glucose. Catalysts 2021, 11, 11. https:/ /dx.doi. org/10.3390/catal11010011

Received: 12 November 2020 Accepted: 21 December 2020 Published: 24 December 2020

Publisher's Note: MDPI stays neutral with regard to jurisdictional claims in published maps and institutional affiliations.

Copyright: (c) 2020 by the authors. Licensee MDPI, Basel, Switzerland. This article is an open access article distributed under the terms and conditions of the Creative Commons Attribution (CC BY) license (https: / / creativecommons.org/ licenses/by/4.0/).

\begin{abstract}
Furfural and 5-hydroxymethylfurfural (HMF) have been identified as promising bioplatform furans that have a wide range of potential applications as biofuels, bioplastics, and biochemicals. Furfural and HMF are typically synthesized from the substrates of $C_{5}$ sugars and $C_{6}$ sugars, respectively. Furfural can also be produced from $\mathrm{C}_{6}$ sugars, which is technically more challenging owing to the higher energy requirement for carbon-carbon bond cleavage. In this study, the simultaneous production of furfural and HMF from glucose was conducted over different binary catalyst systems of Brønsted acids and Lewis acids using $\gamma$-valerolactone (GVL) as the solvent. A promising performance was achieved by a $\mathrm{SnSO}_{4}-\mathrm{H}_{2} \mathrm{SO}_{4}$ coupling catalyst, with an optimized furfural yield of $42 \%$ and an HMF yield of $34 \%$ at $443 \mathrm{~K}$ in GVL. In addition, a kinetics study was performed in order to understand the mechanism of the simultaneous formation of furfural and HMF from glucose at different temperatures and GVL/water ratios. The results showed that the ratio of furfural to HMF production rate at different temperatures (433 to $463 \mathrm{~K}$ ) or GVL/water ratios (90 to $80 \%$ ) was constant close to 1, suggesting that the production of furfural and HMF might follow similar reaction pathways. Finally, the reaction pathway of glucose conversion to furfural and HMF was proposed based on the experimental and kinetics studies.
\end{abstract}

Keywords: glucose conversion; bio-platform chemicals; furfural; 5-HMF; $\gamma$-valerolactone; kinetics

\section{Introduction}

The development of human society has been highly dependent on fossil carbon reserves, which are finite and have a negative environmental impact. Therefore, there is now a growing interest in the development of renewable energy resources, including primary biomass, hydropower, wind energy, and solar energy [1]. Among these, biomass-derived chemicals have been widely studied as a potential alternative to petroleum-based fuels and chemicals. Biomass can be agricultural, commercial, domestic, or industrial wastes [2,3]. Among the various biomass-derived products, furfural and 5-hydroxymethylfurfural (HMF) have received significant attention as promising platform chemicals since they can be utilized as versatile building blocks in the synthesis of various commodity chemicals and fuels [4]. For example, furfural can be converted into biofuels such as 2-methylfuran, 2-methyltetrahydrofuran, and other furans, in which 2-methyltetrahydrofuran can be directly used as a base material for the production of gasoline [5-7]. 2,5-furandioic acid (FDCA), a derivative of HMF, can be used in the polyethylene terephthalate (PET) industry to produce biodegradable plastic materials as a greener alternative [8]. 
Biomass has three main compositions of $\sim 40-50 \%$ cellulose, $\sim 20-30 \%$ hemicellulose, and $\sim 10-30 \%$ lignin. Cellulose primarily comprises hexoses, such as glucose, while hemicellulose substantially comprises pentoses, such as xylose $[9,10]$. HMF is mainly formed from glucose, whereas furfural is mainly formed from xylose [11]. However, the low abundance of xylose in biomass remains the main problem for furfural synthesis. Therefore, the synthesis of furfural from hexoses provides a new way to overcome this problem by providing a single product stream from the total carbohydrate content of biomass, which accounts for a maximum of $80 \%$ of biomass by weight [12]. It should be noted that HMF formation from glucose involves two reaction procedures of isomerization and dehydration. Differently, furfural formation from glucose needs to undergo three processes of isomerization, decarboxylation, and dehydration, which require more energy for the selective decarboxylation from glucose [13]. Therefore, the yield of furfural using glucose as a substrate is generally lower than the HMF yield [14]. To date, the reported studies for furfural production from hexoses showed that a careful selection of solvent and catalyst is crucial in order to reduce the activation energy and improve the yield of furfural from glucose conversion.

Higher furfural production from hexoses has been achieved in the presence of acid catalysts and polar aprotic solvents. Polar aprotic solvents such as lactones and sulfolane were especially active for furfural synthesis. For example, glucose was isomerized to fructose, which was then dehydrated to HMF over Sn-Beta zeolite in the aqueous phase [15]. However, a furfural yield of $69.2 \%$ was achieved from glucose in $\gamma$-valerolactone (GVL) [16]. Given the published studies for converting hexoses to furfural, acid catalysts such as zeolite and $\mathrm{H}_{2} \mathrm{SO}_{4}$ presented an improvement for the selectivity of furfural formation. Particularly, the ratio of Lewis acid and Brønsted acid sites is essential for the conversion of glucose to furfural, and a higher ratio contributed to a higher selectivity of furfural $[13,16]$.

Earlier studies showed that furfural formation competed with HMF formation from hexoses. The distribution patterns of furfural and HMF products varied significantly by changing the catalysts or solvents. For example, the changes of the water proportion in the sulfolane from 0.5 to 0 increased furfural yield from $10 \%$ to $51 \%$ [17]. However, the competition mechanism for furfural and HMF formation was complex and rarely reported. A kinetic study is favorable for the understanding of the complex mechanism. The kinetic study in this work could not only provide access for the understanding of the complex mechanism but also depict their relationship.

In this study, therefore, a few combinations of different homogeneous Brønsted acids and Lewis acids were employed in glucose conversion using GVL as the solvent. In addition, co-catalysts of $\mathrm{SnSO}_{4}$ and $\mathrm{H}_{2} \mathrm{SO}_{4}$ were selected to study the kinetic models for the conversion of glucose into furfural and $\mathrm{HMF}$ in GVL at a range of temperatures and GVL/water ratios. Furthermore, a possible reaction pathway for the co-production of furfural and HMF was proposed.

\section{Results}

\subsection{Synergistic Effect of Lewis and Brønsted Acids}

The furfural and HMF yields achieved in the presence of Brønsted acids $\left(\mathrm{H}_{2} \mathrm{SO}_{4}\right.$, $\mathrm{HCl}, \mathrm{HNO}_{3}$ and $\left.\mathrm{H}_{3} \mathrm{PO}_{4}\right)$ and Lewis acids $\left(\mathrm{SnSO}_{4}, \mathrm{CuSO}_{4}\right.$, and $\left.\mathrm{MnSO}_{4}\right)$ as co-catalysts are presented in Table 1. The coupling of Lewis acid and Brønsted acid achieved higher furfural and HMF yields than the single-acid systems. Regarding the single-acid systems, the presence of only Lewis acid of $\mathrm{SnSO}_{4}(0.014 \mathrm{~mol} / \mathrm{L}$ and $0.028 \mathrm{~mol} / \mathrm{L})$ showed a negligible effect on the conversion of glucose to furfural or HMF under the same reaction conditions, suggesting the poor activity of $\mathrm{SnSO}_{4}$ as a Lewis acid [18]. However, $\mathrm{H}_{2} \mathrm{SO}_{4}$ as a Brønsted acid catalyst gave a small yield of furfural and HMF. The same result has been published, in which a furfural yield of $10 \%$ was obtained from glucose conversion in GVL over $\mathrm{H}_{2} \mathrm{SO}_{4}$ at $448 \mathrm{~K}$ for $30 \mathrm{~min}$ [19]. Despite the slight decrease in HMF yield and glucose conversion, the increase in $\mathrm{H}_{2} \mathrm{SO}_{4}$ concentration from 0.009 to $0.018 \mathrm{~mol} / \mathrm{L}$ led to an obvious increase in furfural yield and selectivity from $7 \%$ and $13 \%$ to $12 \%$ and $24 \%$, respectively. The result indicates that $\mathrm{H}_{2} \mathrm{SO}_{4}$ played an important role in furfural production. 
Table 1. Glucose conversion into furfural and 5-hydroxymethylfurfural (HMF) using single and mixed catalysts. Reaction conditions: $0.0555 \mathrm{~mol} \mathrm{~L}^{-1}$ glucose; $1.8 \mathrm{~mL} \gamma$-valerolactone $(\mathrm{GVL})$; $0.2 \mathrm{~mL}$ water; temperature: $443 \mathrm{~K}$; reaction time: $25 \mathrm{~min}$.

\begin{tabular}{|c|c|c|c|c|c|c|c|}
\hline Entry & $\begin{array}{l}\text { Brønsted Acid } \\
(\mathrm{mol} / \mathrm{L})\end{array}$ & $\begin{array}{l}\text { Lewis Acid } \\
(\mathrm{mol} / \mathrm{L})\end{array}$ & $\begin{array}{c}\text { Furfural } \\
\text { Production (\%) }\end{array}$ & HMF Production (\%) & $\begin{array}{c}\text { Glucose Conversion } \\
(\%)\end{array}$ & $\begin{array}{c}\text { Furfural } \\
\text { Selectivity (\%) }\end{array}$ & $\begin{array}{c}\text { HMF Selectivity } \\
(\%)\end{array}$ \\
\hline 1 & n.a & n.a & n.a & n.a & n.a & n.a & n.a \\
\hline 2 & $\mathrm{H}_{2} \mathrm{SO}_{4}(0.009)$ & n.a & $7 \pm 0.8$ & $8 \pm 1.4$ & $54 \pm 3.9$ & $13 \pm 0.6$ & $15 \pm 1.5$ \\
\hline 3 & $\mathrm{H}_{2} \mathrm{SO}_{4}(0.018)$ & n.a & $12 \pm 1.4$ & $6 \pm 0.5$ & $49 \pm 4.3$ & $24 \pm 0.7$ & $12 \pm 0.1$ \\
\hline 4 & $\mathrm{H}_{2} \mathrm{SO}_{4}(0.018)$ & $\mathrm{MnSO}_{4}(0.014)$ & $4 \pm 0.6$ & $15 \pm 1.2$ & $58 \pm 7.2$ & $14 \pm 0.2$ & $26 \pm 1.2$ \\
\hline 5 & $\mathrm{H}_{2} \mathrm{SO}_{4}(0.018)$ & $\mathrm{CuSO}_{4}(0.014)$ & $24 \pm 0.1$ & $32 \pm 0.3$ & $92 \pm 2.4$ & $26 \pm 0.6$ & $35 \pm 0.6$ \\
\hline 6 & $\mathrm{H}_{2} \mathrm{SO}_{4}(0.018)$ & $\mathrm{SnSO}_{4}(0.014)$ & $33 \pm 2.5$ & $21 \pm 1.8$ & $99 \pm 0.2$ & $33 \pm 2.5$ & $22 \pm 1.3$ \\
\hline 7 & $\mathrm{H}_{2} \mathrm{SO}_{4}(0.018)$ & $\mathrm{SnSO}_{4}(0.028)$ & $29 \pm 1.4$ & $12 \pm 0.3$ & $84 \pm 2.9$ & $36 \pm 0.5$ & $14 \pm 0.1$ \\
\hline 8 & $\mathrm{HCl}(0.018)$ & $\mathrm{SnSO}_{4}(0.014)$ & $15 \pm 1.7$ & $37 \pm 2.3$ & $79 \pm 4.2$ & $19 \pm 1.1$ & $47 \pm 0.4$ \\
\hline 9 & $\mathrm{H}_{3} \mathrm{PO}_{4}(0.018)$ & $\mathrm{SnSO}_{4}(0.014)$ & $1 \pm 0.5$ & $1 \pm 0.6$ & $10 \pm 0.5$ & $10 \pm 4.5$ & $10 \pm 5.5$ \\
\hline 10 & $\mathrm{HNO}_{3}(0.018)$ & $\mathrm{SnSO}_{4}(0.014)$ & $20 \pm 2.1$ & $36 \pm 3.0$ & $76 \pm 1.9$ & $27 \pm 3.2$ & $48 \pm 5.0$ \\
\hline 10 & n.a & $\mathrm{SnSO}_{4}(0.014)$ & n.a & n.a & Trace & n.a & n.a \\
\hline 11 & n.a & $\mathrm{SnSO}_{4}(0.028)$ & n.a & n.a & Trace & n.a & n.a \\
\hline
\end{tabular}

n.a: means no applicable.

Adding $\mathrm{SnSO}_{4}(0.014 \mathrm{~mol} / \mathrm{L})$ into the solvent with $\mathrm{H}_{2} \mathrm{SO}_{4}(0.018 \mathrm{~mol} / \mathrm{L})$ contributed to the almost complete conversion of glucose with a conversion efficiency of $99 \%$, as well as a 2.75 times higher furfural yield of $33 \%$ and 3.5 times higher HMF yield of $21 \%$ (Table 1, entry 6) than those achieved by applying only $\mathrm{H}_{2} \mathrm{SO}_{4}$ as a catalyst in the same reaction condition (Table 1, entry 3). The obvious synergistic effect of $\mathrm{SnSO}_{4}$ and $\mathrm{H}_{2} \mathrm{SO}_{4}$ could be observed during the degradation of glucose to furfural and HMF. The possible reason is that the active Lewis acid of $\mathrm{SnSO}_{4}$ was proven to be more active in promoting the isomerization of $\mathrm{C} 6$ sugar to the intermediates [18], while a Brønsted acid of $\mathrm{H}_{2} \mathrm{SO}_{4}$ was mainly responsible for the dehydration and the protonation of hydroxyl groups to form furfural and HMF $[20,21]$. As a consequence, a synergy was created for the selective conversion of glucose to furfural and $\mathrm{HMF}$ with the co-existence of $\mathrm{SnSO}_{4}$ and $\mathrm{H}_{2} \mathrm{SO}_{4}$.

The effect of other different Brønsted acids is also presented in Table $1 . \mathrm{HCl}$ and $\mathrm{HNO}_{3}$ can effectively achieve decent glucose conversions of $79 \%$ and $76 \%$, respectively (entry 8 and 10). In contrast, $\mathrm{H}_{3} \mathrm{PO}_{4}$, the weakest and non-oxide acid, suppressed the conversion of glucose (Entry 9). On the other hand, the highest and second-highest furfural selectivities were obtained using oxidizing acids such as $\mathrm{H}_{2} \mathrm{SO}_{4}$ and $\mathrm{HNO}_{3}$, while $\mathrm{HCl}$ as the strongest acid promoted HMF selectivity. This indicates that oxygenates were more promising in promoting the $\mathrm{C}-\mathrm{C}$ bond cleavage and, subsequently, the furfural production, compared with a non-oxide acid like $\mathrm{HCl}$. In brief, the selection for Brønsted acids determines glucose conversion efficiency and selectivity of furfural and HMF.

Additionally, the yield of HMF and furfural and even their ratio were affected by the metal cations of Lewis acids, such as $\mathrm{Sn}^{2+}, \mathrm{Cu}^{2+}$, and $\mathrm{Mn}^{2+}$, with the same valance state. Comparatively, the $\mathrm{CuSO}_{4} / \mathrm{H}_{2} \mathrm{SO}_{4}$ system obtained the highest $\mathrm{HMF}$ conversion and selectivity, while $\mathrm{SnSO}_{4} / \mathrm{H}_{2} \mathrm{SO}_{4}$ achieved the highest furfural conversion and selectivity. Therefore, the substitution of $\mathrm{Sn}^{2+}$ by $\mathrm{Cu}^{2+}$ resulted in the increase in HMF yield from $21 \%$ (Table 1, entry 6 ) to $32 \%$ (Table 1, entry 5), but furfural yield was decreased from $33 \%$ (Table 1 , entry 6) to $24 \%$ (Table 1 , entry 5). Besides, the $\mathrm{MnSO}_{4} / \mathrm{H}_{2} \mathrm{SO}_{4}$ system provided much lower furfural ( $4 \%$, Table 1 , entry 4$)$ and $\operatorname{HMF}(15 \%$, Table 1 , entry 4$)$ yields. The result suggested that different metal cations could also alter the main reaction pathway of glucose degradation.

\subsection{Kinetics Model}

Based on the catalyst filtering results, the $\mathrm{SnSO}_{4} / \mathrm{H}_{2} \mathrm{SO}_{4}$ catalytic system was selected to study the kinetics, mechanism, and GVL effect for glucose conversion into furfural and HMF. Figure 1 presents the fitting results between the experimental data and the simulated data from models for glucose conversion, furfural production, and HMF production at various temperatures (433 to $463 \mathrm{~K}$ ). The R-squared values for all simulations are greater than 0.9 , indicating a good fit between the model and experimental data. 


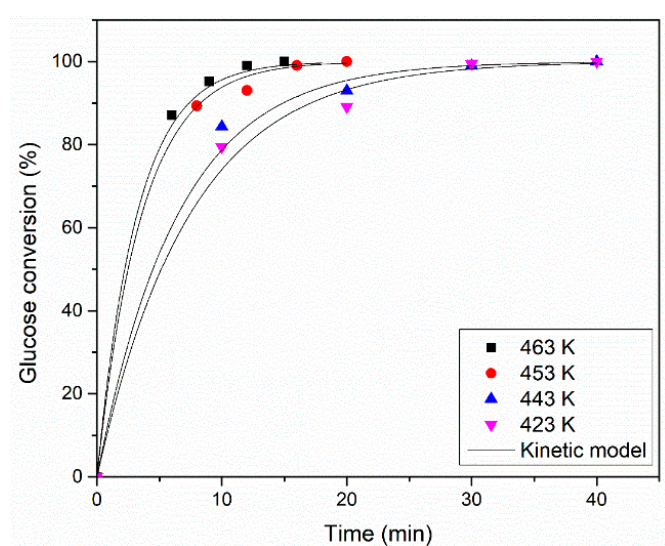

(a)

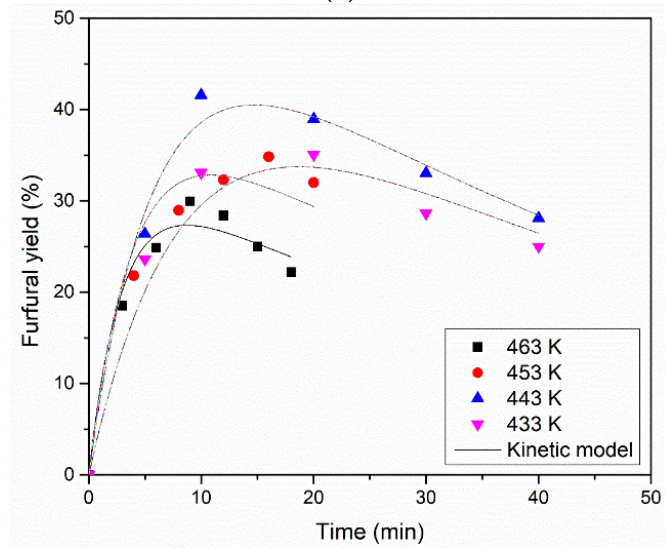

(b)

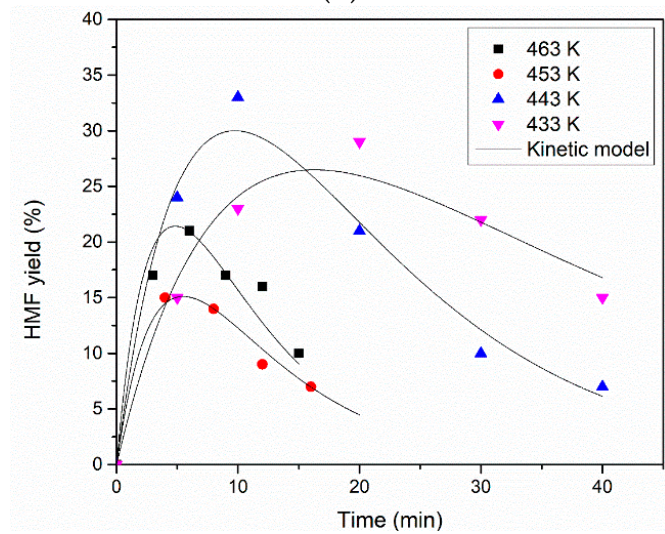

(c)

Figure 1. Comparison of experimental data and kinetic models for (a) glucose conversion and the production yields of (b) furfural production and (c) HMF production as a function of temperature. Reaction conditions: $0.0555 \mathrm{~mol} \mathrm{~L}-1$ glucose; $1.6 \mathrm{~mL} \mathrm{GVL}$; $0.4 \mathrm{~mL}$ water; $0.1 \mathrm{wt} \% \mathrm{H}_{2} \mathrm{SO}_{4}$; and $0.014 \mathrm{~mol} \mathrm{~L}^{-1} \mathrm{SnSO}_{4}$.

The temperature had a significant effect on glucose conversion and furfural and HMF production. The escalating temperature (from 433 to $463 \mathrm{~K}$ ) shortened the reaction time from $40 \mathrm{~min}$ to $12 \mathrm{~min}$ to achieve a full glucose conversion (Figure 1a). However, higher temperatures were detrimental for furfural and HMF production. For example, the maximum furfural yield obtained at $443 \mathrm{~K}$ was $42 \%$, higher than the $30 \%$ achieved at 463 $\mathrm{K}$. The effect of temperature on the variety of glucose conversion and furfural and HMF production was demonstrated by the kinetic results (Tables 2 and 3). 
Table 2. Kinetic parameters for the conversion of glucose into HMF and furfural at different temperatures.

\begin{tabular}{ccccc}
\hline Temp. & $\mathbf{4 3 3} \mathbf{K}$ & $\mathbf{4 4 3} \mathbf{K}$ & $\mathbf{4 5 3} \mathbf{K}$ & $\mathbf{4 6 3} \mathbf{K}$ \\
\hline $\mathrm{k}_{\mathrm{G}}$ & 0.103 & 0.169 & 0.254 & 0.338 \\
$\mathrm{k}_{1}$ & 0.0518 & 0.0849 & 0.0976 & 0.121 \\
$\mathrm{k}_{2}$ & 0.0466 & 0.0713 & 0.076 & 0.124 \\
$\mathrm{k}_{3}$ & 0.0185 & 0.0194 & 0.0205 & 0.0213 \\
$\mathrm{k}_{4}$ & 0.0329 & 0.0761 & 0.115 & 0.138 \\
$\mathrm{k}_{5}$ & 0.0046 & 0.0128 & 0.0804 & 0.093 \\
$\mathrm{k}_{1} / \mathrm{k}_{2}$ & 1.1 & 1.2 & 1.3 & 1.0 \\
$\mathrm{k}_{5} / \mathrm{k}_{\mathrm{G}}$ & 0.04 & 0.08 & 0.32 & 0.30 \\
$\mathrm{k}_{1} / \mathrm{k}_{3}$ & 2.8 & 4.4 & 4.8 & 5.7 \\
$\mathrm{k}_{2} / \mathrm{k}_{4}$ & 1.4 & 0.9 & 0.7 & 0.9 \\
$\mathrm{k}_{4} / \mathrm{k}_{3}$ & 1.8 & 3.9 & 5.6 & 6.5 \\
\hline
\end{tabular}

Table 3. Kinetic parameters for the conversion of glucose into furfural at different temperatures.

\begin{tabular}{ccccccc}
\hline Temperature & $\mathbf{k}_{\mathbf{G}}$ & $\mathbf{k}_{\mathbf{1}}$ & $\mathbf{k}_{\mathbf{2}}$ & $\mathbf{k}_{\mathbf{3}}$ & $\mathbf{k}_{\mathbf{4}}$ & $\mathbf{k}_{\mathbf{5}}$ \\
\hline $\mathrm{E}_{\mathrm{a}}\left(\mathrm{kJ} \mathrm{mol}^{-1}\right)$ & 66.9 & 44.9 & 49.9 & 8.0 & 79.0 & 181.5 \\
$\mathrm{~A}\left(\mathrm{~min}^{-1}\right)$ & $1.17 \times 10^{7}$ & $1.49 \times 10^{4}$ & $5.02 \times 10^{4}$ & $5.91 \times 10^{0}$ & $1.32 \times 10^{8}$ & $3.92 \times 10^{19}$ \\
$\mathrm{R}^{2}$ & 0.991 & 0.935 & 0.932 & 0.997 & 0.921 & 0.927 \\
\hline
\end{tabular}

All production and degradation rates $\left(\mathrm{k}_{\mathrm{i}}\right)$ increased with the escalating temperatures (Table 2). Therefore, the comparisons between all reaction rates are significant for identifying which reaction rates decisively affected the furfural or HMF production. Given that, some factors were established, such as $\mathrm{k}_{1} / \mathrm{k}_{3}, \mathrm{k}_{2} / \mathrm{k}_{4}, \mathrm{k}_{1} / \mathrm{k}_{2}, \mathrm{k}_{4} / \mathrm{k}_{3}$, and $\mathrm{k}_{5} / \mathrm{k}_{\mathrm{G}}$ (Table 2 ). In detail, $\mathrm{k}_{1} / \mathrm{k}_{3}$ and $\mathrm{k}_{2} / \mathrm{k}_{4}$ were used to evaluate the furfural or HMF production efficiency; $\mathrm{k}_{1} / \mathrm{k}_{2}$ and $\mathrm{k}_{4} / \mathrm{k}_{3}$ were employed to compare furfural and HMF in terms of their production and degradation processes; the factor of $\mathrm{k}_{5} / \mathrm{k}_{\mathrm{G}}$ was used to show glucose side reactions.

It was observed from $\mathrm{k}_{5} / \mathrm{k}_{\mathrm{G}}$ that the glucose side reaction intensively competed with furfural and HMF production. $\mathrm{k}_{5} / \mathrm{k}_{\mathrm{G}}$ increased with rising temperature, suggesting that the glucose side reaction was enhanced with the increase in reaction temperature. As a result, the formation of furfural and HMF was suppressed, which could explain the reduction of furfural and HMF yield at higher temperatures, as displayed in Figure 1b,c. Furthermore, the decrease in HMF yield could be explained by another reason for the poor HMF thermal stability. It could be observed that after the maximum formation peak, furfural yields decreased gradually (Figure 1b), while HMF yields decreased sharply (Figure 1c). From the perspective of kinetics, $k_{2} / k_{4}$ was reduced from 1.4 to 0.9 with increasing temperatures, which indicates that HMF decomposition rates are quicker than its formation rates, especially at higher temperatures. The results of apparent activation energies $\left(E_{a}\right)$ in Table 3 further support that the side reactions of glucose and HMF were easily promoted by increasing temperature. It could be observed that the highest apparent activation energy was achieved by glucose side reactions $\left(\mathrm{E}_{\mathrm{a} 5}=181.5 \mathrm{~kJ} \mathrm{~mol}^{-1}\right)$ followed by HMF decomposition $\left(\mathrm{E}_{\mathrm{a} 4}=79.0 \mathrm{~kJ} \mathrm{~mol}^{-1}\right)$, which implies that the side reactions of glucose and HMF are sensitive to the temperature changes. In contrast, the degradation of furfural to humin shows the lowest apparent activation energies of $8.0 \mathrm{~kJ} \mathrm{~mol}^{-1}$. This suggests that changing temperature did not significantly promote the side reaction of furfural, which is consistent with the experimental result (Figure $1 \mathrm{~b}$ ).

Besides, the factor of $\mathrm{k}_{1} / \mathrm{k}_{2}$ was constantly kept at around 1, which was not evidently affected by the temperatures. This indicates that furfural and HMF might be produced through similar and non-interacting reaction pathways. More mechanism details will be presented in the following mechanism section. Overall, given the fact that long reaction time is detrimental for furfural and HMF production regardless of their better glucose conversion, the optimized reaction condition is registered at $443 \mathrm{~K}$ for $10 \mathrm{~min}$. Therefore, a careful selection of reaction temperature is crucial to maximize the yields of furfural and $\mathrm{HMF}$. 


\subsection{Effect of Solvent}

As mentioned, the increase in the solvent sulfolane proportion in water increased furfural yield from $10 \%$ to $51 \%$ [13], which is possible because the changes of the interactions between reactants and solvents alter the reaction pathway, reaction rate, and transition stability in glucose conversion [16,22-24]. Therefore, it is necessary to understand the effect and mechanism of solvents on glucose conversion into furfural and HMF. In this paper, solvents with various GVL/water ratios were employed and a kinetics study was conducted. Figure 2 shows the fitting results between experimental data and simulated data. The R-squared values for all simulations are greater than 0.9 .

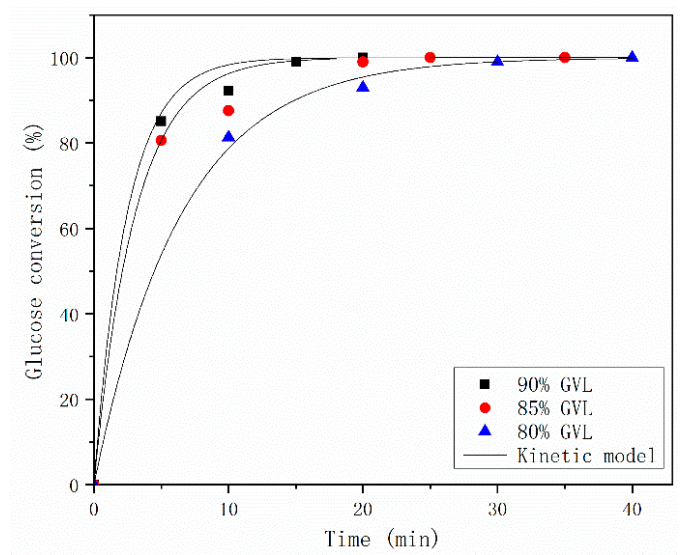

(a)

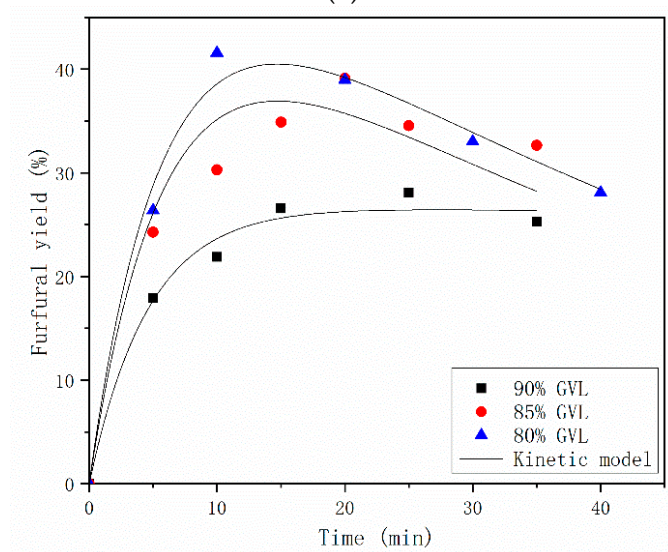

(b)

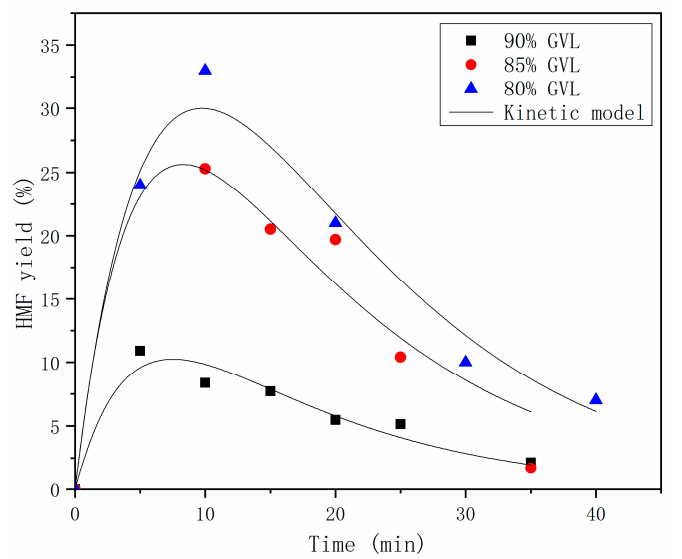

(c)

Figure 2. Comparison of experimental data and kinetic models for (a) glucose conversion, (b) furfural production, and (c) HMF production as a function of different ratios of GVL to water. Reaction conditions: temperature: $443 \mathrm{~K} ; 0.0555 \mathrm{~mol} \mathrm{~L}^{-1}$ glucose; $0.1 \mathrm{wt} \% \mathrm{H}_{2} \mathrm{SO}_{4}$; and $0.014 \mathrm{~mol} / \mathrm{L} \mathrm{SnSO}_{4}$. 
Figure 2a shows that a higher GVL content promoted glucose conversion, where glucose was rapidly consumed. However, a higher GVL content had an adverse effect on the total production of furfural and HMF. For instance, the total production was decreased from 42 to $33 \%$ for furfural, and from 35 to $11 \%$ for HMF with the increase in GVL contents from 80 to $90 \%$. The reason could be revealed by the kinetic results in Table 4 . The factor of $\mathrm{k}_{5} / \mathrm{k}_{\mathrm{G}}$ significantly increased with an increase in GVL content. In other words, glucose side reactions competed with furfural and HMF production, and these competitions became more vigorous as GVL contents increased.

Table 4. Kinetic parameters for the conversion of glucose to furfural at a different GVL content levels.

\begin{tabular}{cccc}
\hline GVL/Water Ratio & $\mathbf{9 0 \%}$ & $\mathbf{8 5 \%}$ & $\mathbf{8 0 \%}$ \\
\hline $\mathrm{k}_{\mathrm{G}}$ & 0.315 & 0.197 & 0.169 \\
$\mathrm{k}_{1}$ & 0.0578 & 0.07679 & 0.0849 \\
$\mathrm{k}_{2}$ & 0.0486 & 0.0695 & 0.0713 \\
$\mathrm{k}_{3}$ & 0.0006 & 0.00484 & 0.0194 \\
$\mathrm{k}_{4}$ & 0.0748 & 0.08966 & 0.0761 \\
$\mathrm{k}_{5}$ & 0.2186 & 0.0507 & 0.0128 \\
$\mathrm{k}_{1} / \mathrm{k}_{2}$ & 1.2 & 1.1 & 1.2 \\
$\mathrm{k}_{5} / \mathrm{k}_{\mathrm{G}}$ & 0.69 & 0.26 & 0.08 \\
$\mathrm{k}_{1} / \mathrm{k}_{3}$ & 96.3 & 15.9 & 4.4 \\
$\mathrm{k}_{2} / \mathrm{k}_{4}$ & 0.6 & 0.8 & 0.9 \\
$\mathrm{k}_{4} / \mathrm{k}_{3}$ & 124.7 & 18.5 & 3.9 \\
\hline
\end{tabular}

Interestingly, the production of furfural did not show a sharp decrease after the maximum formation peak at higher GVL contents as HMF production did, suggesting that a higher GVL content could prevent the further degradation of furfural. The phenomenon could be explained by the kinetics results in Table 4 . On the one hand, $\mathrm{k}_{3}$ decreased visibly, while $\mathrm{k}_{4}$ did not show obvious change with the increase in GVL content. This result suggested that the decomposition of furfural was inhibited at higher GVL content levels. On the other hand, a positive correlation was found between $\mathrm{k}_{1} / \mathrm{k}_{3}$ and GVL content, and the $\mathrm{k}_{1} / \mathrm{k}_{3}$ was increased from 4.4 to 96.3 with an increase in the GVL content, indicating that the effect of furfural decomposition on the furfural yield could be neglected at higher GVL contents.

Overall, it can be concluded that the distribution between the expected products and undesirable byproducts could be altered by changing the ratio of GVL to water. At the same time, a higher GVL content could suppress the further decomposition of furfural, contributing to the efficient and stable production of furfural.

\subsection{Possible Reaction Pathway}

Three reaction pathways (Pathway 1, 2, and 4) of glucose conversion into furfural have been proposed in previous studies, as presented in Figure 3. Gürbüz et al. have proposed that glucose could be initially converted to HMF, which then loses carbon as formaldehyde to form furfural (Pathway 1) [19]. However, in this study, when HMF was used as the feedstock in the $\mathrm{SnSO}_{4} / \mathrm{H}_{2} \mathrm{SO}_{4}$ system, furfural was not detected in the final products (Table S4, Supplementary Materials), which excluded the possibility of this reaction pathway. Hu et al. applied density functional theory (DFT) calculations to study the formation mechanism of furfural from glucose. They proposed that the formation of HMF and furfural from glucose follows similar reaction pathways in theory, with 3-deoxyglucosone (Pathway 4) or fructose (Pathway 2) as the key intermediate [25]. Our kinetics results also showed that furfural and HMF have very similar production rate constants and reaction pathways. In Pathway 2, glucose is first transformed into fructose. Then, furfural is produced from fructose by losing carbon as formaldehyde and subsequently undergoing three dehydration processes [22,26,27]. However, fructose was not observed as an intermediate along with glucose conversion experiments in this study. In addition, the degradation of fructose as the substrate was conducted in the $\mathrm{SnSO}_{4} / \mathrm{H}_{2} \mathrm{SO}_{4}$ system in this 
study. A distinguished product composition with $49 \% \mathrm{HMF}$ and $9 \%$ furfural was obtained (Table S4, Supplementary Materials), compared with 21\% HMF and 33\% furfural using glucose as a substrate. Therefore, the production of furfural from glucose is also unlikely to follow the fructose pathway in this study. Moreover, the possibility of Pathway 3 in which HMF is generated from fructose is also quite low due to the absence of fructose as an intermediate. Furthermore, 3-deoxy-glucosone was detected in the reacted mixture using Liquid Chromatography with tandem mass spectrometry (LC-MS/MS) (Figures S4-S7, Supplementary Materials). Therefore, we proposed that furfural and HMF were formed from glucose via 3-deoxy-glucosone as a key intermediate in this system via pathway 4 . Then, 3-deoxy-glucosone was transformed into a double-bond intermediate with poor stability, which would quickly lose carbon as formaldehyde to form furfural [28].

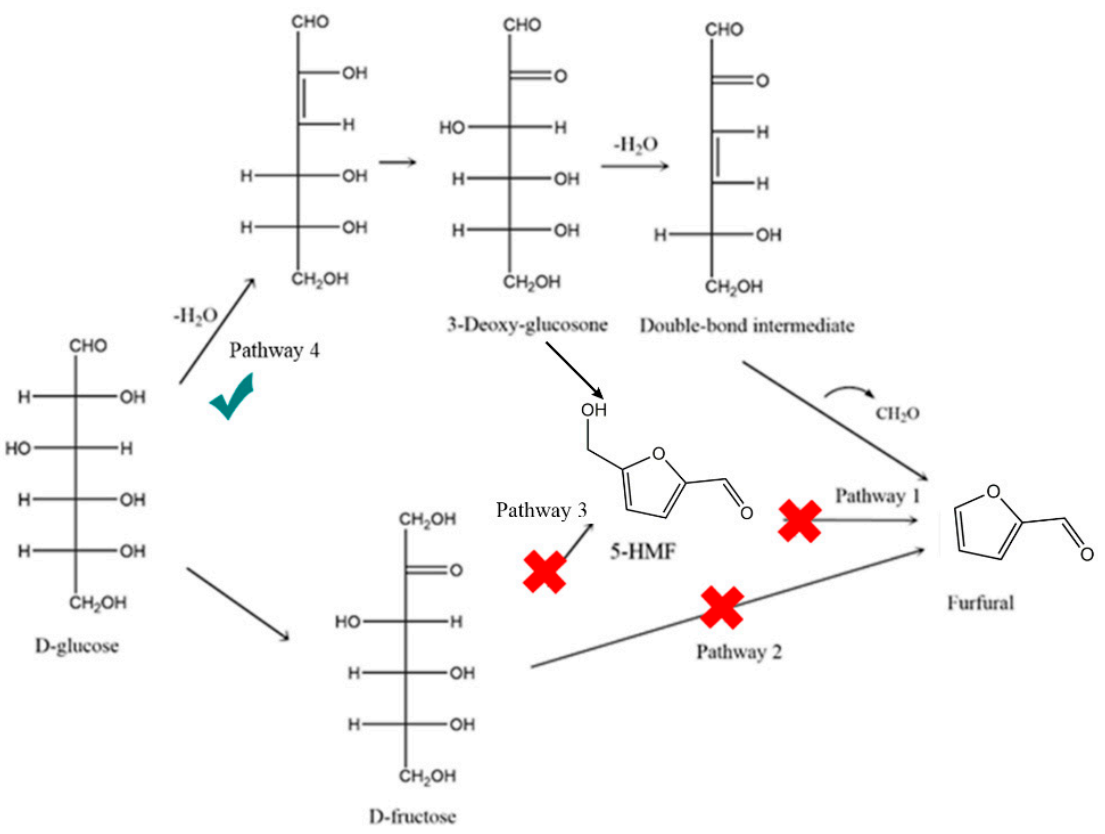

Figure 3. Possible reaction pathway for the furfural and HMF production from glucose.

\section{Materials and Methods}

\subsection{Materials}

$\mathrm{D}(+)$-Glucose (Sigma-Aldrich, St. Louis, MO, USA, 99.5\%), fructose (Macklin, Shanghai, China, 99\%), HMF (Sigma-Aldrich, St. Louis, MO, USA, 99\%), furfural (Macklin, Shanghai, China, 99\%), GVL (Macklin, Shanghai, China, 98\%), 2,4-Dinitrophenylhydrazine (DNPH)-silica cartridges (Energy Chemical, Shanghai, China, 37\%), formaldehyde (Energy Chemical, Shanghai, 37\%), sulfuric acid (Meryer, Shanghai, China, $\geq 98 \%$ ), hydrochloric acid (Meryer, Shanghai, China, $\geq 36 \%$ ), phosphoric acid (Meryer, Shanghai, China, $\geq 95 \%$ ), $\mathrm{SnSO} 4$ (Meryer, Shanghai, China, $99 \%$ ), $\mathrm{MnSO}_{4}$, and $\mathrm{CuSO}_{4}$ were all purchased from Tianjin Jiangtian Co., Tianjin, China.

\subsection{Catalytic Reactions}

All experiments, including glucose conversion, furfural production, and HMF production, were conducted in a thick-walled glass reactor $(8 \mathrm{~mL})$ with a Teflon screw top. Different ratios of GVL and water and the required amount of feedstock (glucose, furfural, and $\mathrm{HMF}$ ) and catalysts, as well as a $5 \mathrm{~cm}$ stir bar, were added into the reactor in sequence. Then, the reactor was put in a preheated oil bath at different temperatures for the target reaction time. After each reaction, the sample was directly quenched in an ice bath and subsequently diluted using water. Then, the sample was filtered through a $0.22 \mu \mathrm{m}$ syringe filter and analyzed using a high-performance liquid chromatography (HPLC) system. All experiments were performed in duplicate or triplicate. The formaldehyde collection set-up 
was used to collect the formaldehyde product in the gas phase (Scheme 1). After the reaction, $\mathrm{N}_{2}$ with a flow rate of $5 \mathrm{~mL} \mathrm{~min}^{-1}$ was employed to purge the reactor, which, together with the products, was then passed through DNPN-silica cartridges for $30 \mathrm{~min}$. After collection, the DNPN-silica cartridges were washed with $5 \mathrm{~mL}$ acetonitrile (HPLC purity) at approximately $0.5 \mathrm{~mL} \mathrm{~min}^{-1}$, and the solvent was analyzed by HPLC.

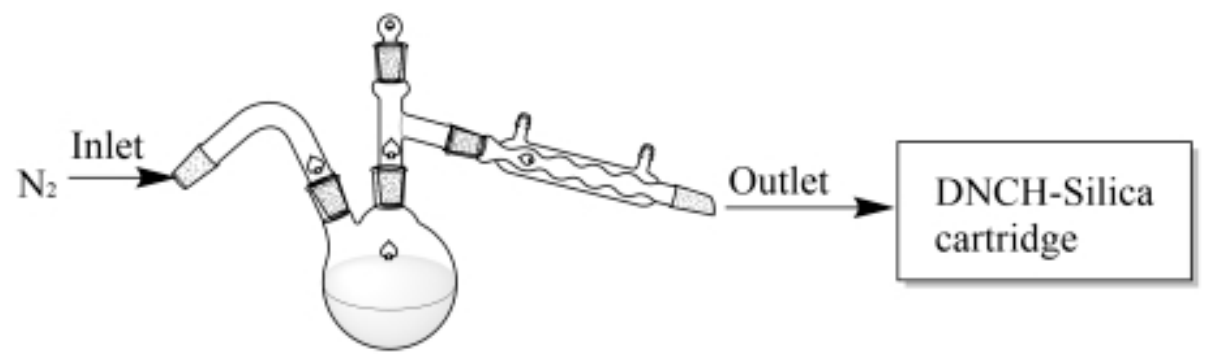

Scheme 1. Formaldehyde gas collection set-up diagram (reaction condition: glucose: $1.11 \mathrm{~mol} \mathrm{~L}^{-1}$, $32 \mathrm{~mL} \mathrm{GVL}, 8 \mathrm{~mL}$ water; $0.1 \mathrm{wt} \% \mathrm{H}_{2} \mathrm{SO}_{4} ; 0.014 \mathrm{~mol} \mathrm{~L}^{-1} \mathrm{SnSO}_{4}$ ).

\subsection{Determination of Glucose, Furfural, HMF, and Formaldehyde}

Glucose was analyzed using an HPLC apparatus equipped with a refractive index detector and an Agilent (Santa Clara, California, UAS) Zorbax Amide column at a sample injection volume of $20 \mu \mathrm{L}$. A solution of acetonitrile/distilled water $(60: 40, v / v)$ was used as the mobile phase at a flow rate of $1.0 \mathrm{~mL} \mathrm{~min}{ }^{-1}$.

Furfural, HMF, and formaldehyde were analyzed using a 1200 HPLC system equipped with an Agilent XDB-C18 column and a UV-Vis photodiode array detector with a sample injection volume of $20 \mu \mathrm{L}$. A solution of acetonitrile/water $(15: 85, v / v)$ was used as the mobile phase for furfural $(280 \mathrm{~nm})$ and $\mathrm{HMF}(280 \mathrm{~nm})$ analysis at a flow rate of $1 \mathrm{~mL}$ $\mathrm{min}^{-1}$, whereas acetonitrile/water $(40: 60, v / v)$ was used for formaldehyde quantification (355 nm).

The glucose conversion, furfural degradation, HMF degradation, furfural yield, HMF yield, furfural selectivity, and 5-HMF selectivity were calculated by Equations (1)-(5), as follows.

$$
\begin{aligned}
& \text { Glucose conversion }\left(\mathrm{X}_{\mathrm{GLU}} \%\right)=\frac{\text { moles of converted glucose }}{\text { moles of starting glucose }} \times 100 \% \\
& \text { Furfural yield }(\%)=\frac{\text { moles of produced furfural }}{\text { moles of starting glucose }} \times 100 \% \\
& \mathrm{HMF} \text { yield }(\%)=\frac{\text { moles of produced } \mathrm{HMF}}{\text { moles of starting glucose }} \times 100 \% \\
& \text { Furfural selectivity }(\%)=\frac{\text { moles of produced furfural }}{\text { moles of converted glucose }} \times 100 \% \\
& \text { HMF selectivity }(\%)=\frac{\text { moles of produced HMF }}{\text { moles of converted glucose }} \times 100 \%
\end{aligned}
$$

\subsection{Kinetic Calculation}

Based on the reported study on furfural and HMF formation, the simplified reaction in Scheme 2 was developed to describe the behavior of glucose, furfural, and HMF degradation as well as furfural and HMF production. The kinetic model with a pseudo first-order mechanism was considered. The validity of the model was tested by fitting the proposed rate equations to the experimental data [29-31]. As reference, similar published kinetic models were presented and compared in Table S5. 


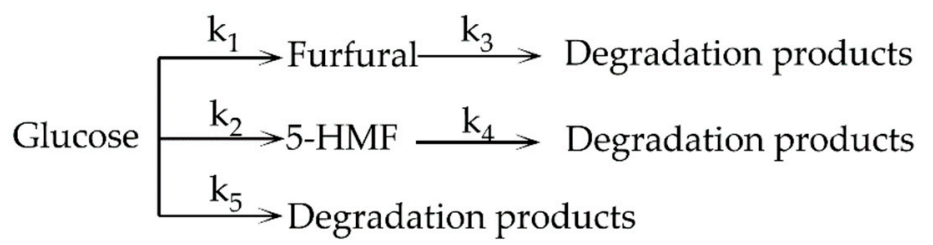

Scheme 2. Simplified reaction scheme for the conversion of glucose.

Five key chemical reaction steps for glucose conversion have been considered in the kinetic model: (1) the conversion of glucose to HMF; (2) the conversion of glucose to furfural; (3) the conversion of glucose to other degradation products; (4) the further degradation of HMF; and (5) the further degradation of furfural.

The kinetic model of the glucose conversion reaction was proposed on the following assumptions.

(1) The intermediates of furfural production and HMF production have not been included in the kinetic model.

(2) All unidentified products are considered to be degradation products (humin).

(3) All reactions are irreversible.

The degradation rates of glucose, furfural, and HMF in Equations (6)-(9) are developed.

$$
\begin{gathered}
\frac{\mathrm{dC}_{\mathrm{GLU}}}{\mathrm{dt}}=\left(\mathrm{k}_{1}+\mathrm{k}_{2}+\mathrm{k}_{5}\right) \mathrm{C}_{\mathrm{GLU}} \\
\frac{\mathrm{d} \mathrm{C}_{\mathrm{FUR}}}{\mathrm{dt}}=\mathrm{k}_{1} \mathrm{C}_{\mathrm{GLU}}-\mathrm{k}_{3} \mathrm{C}_{\mathrm{FUR}} \\
\frac{\mathrm{d} \mathrm{C}_{\mathrm{HMF}}}{\mathrm{dt}}=\mathrm{k}_{2} \mathrm{C}_{\mathrm{GLU}}-\mathrm{k}_{4} \mathrm{C}_{\mathrm{HMF}} \\
\mathrm{k}_{\mathrm{GLU}}=\mathrm{k}_{1}+\mathrm{k}_{2}+\mathrm{k}_{5}
\end{gathered}
$$

where GLU represents glucose, HMF represents HMF, and FUR represents furfural.

The concentrations of glucose, furfural, and HMF over time were described as Equations (10)-(12) with $\mathrm{C}_{\mathrm{GLUt}}=0.0555 \mathrm{~mol} \mathrm{~L}^{-1}$ and $\mathrm{C}_{\mathrm{HMF}}=\mathrm{C}_{\mathrm{FUR}}=0$ at $\mathrm{t}=0$ :

$$
\begin{gathered}
\mathrm{C}_{\mathrm{GLU}}=\mathrm{C}_{\mathrm{GLU} 0}\left(1-\mathrm{e}^{-\mathrm{k}_{\mathrm{GLU}} \mathrm{t}}\right) \\
\mathrm{C}_{\mathrm{FUR}}=\frac{\mathrm{k}_{1} \mathrm{C}_{\mathrm{GLU} 0}}{\mathrm{k}_{3}-\mathrm{k}_{\mathrm{GLU}}}\left[\mathrm{e}^{-\mathrm{k}_{\mathrm{GLU}} \mathrm{t}}-\mathrm{e}^{-\mathrm{k}_{3} \mathrm{t}}\right] \\
\mathrm{C}_{\mathrm{HMF}}=\frac{\mathrm{k}_{2} \mathrm{C}_{\mathrm{GLU}}}{\mathrm{k}_{4}-\mathrm{k}_{\mathrm{GLU}}}\left[\mathrm{e}^{-\mathrm{k}_{\mathrm{GLU}} \mathrm{t}}-\mathrm{e}^{-\mathrm{k}_{4} \mathrm{t}}\right]
\end{gathered}
$$

The Arrhenius equation in Equation (13) was used to calculate the activation energy $\left(E_{a}\right)$ and evaluate the effect temperature $(T)$ on the rate constants $(k)$ :

$$
\ln \mathrm{k}=\ln \mathrm{A}-\frac{\mathrm{E}_{\mathrm{a}}}{\mathrm{RT}}
$$

where a corresponds to pre-exponential factor $\left(\mathrm{min}^{-1}\right), \mathrm{k}$ is the reaction rate constant $\left(\mathrm{min}^{-1}\right)$, $E_{a}$ is the activation energy $\left(\mathrm{kJ} \mathrm{mol}^{-1}\right), \mathrm{R}$ is the universal gas constant $\left(\mathrm{kJ}^{-1} \mathrm{~mol}^{-1} \mathrm{~K}^{-1}\right)$, and $\mathrm{T}$ is the temperature $(\mathrm{K})$.

The reaction rate constants $\left(\mathrm{k}_{\mathrm{i}}\right)$ are determined according to previous studies, as follows [29-31]:

(1) The conversion rate constants for glucose $\left(\mathrm{k}_{\mathrm{G}}\right)$ were obtained using a nonlinear curve fitting, as Equation (10), where the data are from Figure 1a.

(2) The formation rate constants of furfural $\left(\mathrm{k}_{1}\right)$ and $\operatorname{HMF}\left(\mathrm{k}_{2}\right)$ and the degradation rate constants of furfural $\left(\mathrm{k}_{3}\right)$ and $\operatorname{HMF}\left(\mathrm{k}_{4}\right)$ were obtained using a nonlinear curve fitting, as Equations (11) and (12), where the data are from Figure 1b,c. 
(3) The formation of other degradation products $\left(\mathrm{k}_{5}\right)$ was calculated using Equation (9) by subtracting the sum of $\mathrm{k}_{1}$ and $\mathrm{k}_{2}$ from $\mathrm{k}_{\mathrm{G}}$.

The A and Ea were obtained from Arrhenius rate data plots, as shown in Figure S1, Supplementary Materials.

As a comparison, another reported method was also employed to calculate the above parameters from experimental data as given in Figure S1 to S3 and Table S2, Supplementary Materials [30].

\section{Conclusions}

In this study, the performance of different co-catalyst systems of Brønsted acid and Lewis acid on the selective conversion of glucose to furfural and HMF was studied, as well as the effect of temperature and solvent composition (different ratios of GVL/water mixtures). In addition, a kinetic model, based on the pseudo first-order kinetics, was proposed to understand the complex mechanism for glucose conversion to furfural and HMF. The result demonstrated that the co-catalyst systems could effectively promote the selective conversion of glucose into furfural and HMF within a short time in GVL/water mixtures. It has been found that strong oxidizing Brønsted acid such as $\mathrm{H}_{2} \mathrm{SO}_{4}$ coupling with appropriate Lewis acid such as $\mathrm{SnSO}_{4}$ could enhance furfural production while a combination of $\mathrm{HCl}$ with $\mathrm{SnSO}_{4}$ or $\mathrm{H}_{2} \mathrm{SO}_{4}$ with $\mathrm{CuSO}_{4}$ was more favorable for $\mathrm{HMF}$ production. Given that, the selection for Brønsted acids determines glucose conversion efficiency and the selectivity of furfural and HMF. The highest furfural and HMF yields of $42 \%$ and $34 \%$ were obtained in the $\mathrm{SnSO}_{4} / \mathrm{H}_{2} \mathrm{SO}_{4}$-catalyzed system at $80 \% \mathrm{GVL}$, for $10 \mathrm{~min}$ at $443 \mathrm{~K}$. Besides, the reaction temperature and ratios of GVL to water also exhibited complex effects on the conversion of glucose and the production of furfural and HMF. High temperatures provided a low yield of furfural and HMF, which is mainly due to an increased humin production rate from glucose and HMF based on the kinetics study. Meanwhile, GVL could change the product distribution by altering the ratio of glucose conversion into expected products to degradation products. A higher ratio of GVL/water promoted the conversion of glucose, which, in contrast, resulted in a lower yield of furfural and HMF due to the rapid increase in HMF and glucose side reactions. In addition, the activation energies in this study are lower than in previous reports. Kinetics results showed that the ratio of furfural and HMF production rate at different temperatures (433 to $463 \mathrm{~K}$ ) or water/GVL ratio (90 to $80 \%$ ) was constant close to 1, suggesting that the production of furfural and HMF might follow similar reaction pathways. Based on the results of kinetic and experiments, it is proposed that the reaction pathway of furfural and HMF production from glucose is via 3-deoxy-glucosone as the key intermediate.

Supplementary Materials: The following are available online at https:/ /www.mdpi.com/2073-434 4/11/1/11/s1, Figure S1: Arrhenius plots of ln (ki) versus 1/T; Figure S2: -Ln(1-X) versus reaction time for (a) furfural degradation and (b) HMF degradation over different temperatures; Figure S3: -Ln(1-X) versus reaction time for (a) furfural conversion and (b) 5-HMF conversion based on the mixed catalyzed system over different ratios of GVL to water; Figure S4: 3-DG determination mechanism; Figure S5: LC-MS spectra of m/z 285.12 (DAN-3-DG) and its fracture process; Figure S6: MS spectra of m/z 285.12 (DAN-3-DG) and corresponding structures; Figure S7: Fragments of DAN-3-DG; Table S1: Kinetic parameters for the conversion of glucose into HMF and furfural at different temperatures; Table S2: Kinetic parameters for the conversion of glucose to furfural at a different water content; Table S3: Glucose conversions into furfural and 5-HMF using single and mixed catalysts; Table S4: Glucose conversions into furfural and 5-HMF using single and mixed catalysts; Table S5: Comparison with previous kinetic models.

Author Contributions: O.H. contributed to the literature search, figures, study design, experiments, data collection, data analysis, data interpretation, writing. Y.Z. performed some experiments and analyzed the products. N.Y. and W.L. provided support for product analysis. P.C. and Q.W. reviewed and edited the original draft. P.W., L.L., and H.Y. supervised the research. All authors have read and agreed to the published version of the manuscript. 
Funding: This work was financially supported by the Major National Science and Technology Projects of China on Water Pollution Control and Treatment (2012ZX07501002-001), National Natural Science Foundation of China (BE210751), National Natural Science Foundation of China (22006075), research on the index system of cleaner production performance evaluation of liquor brewing industrial based on LCA (CP-2018-YB10), open research fund program of key laboratory of cleaner production and integrated resource utilization of china national light industry, Tianjin Development Program for Innovation and Entrepreneurship. Champagne is grateful for funding provided by the China State Administration of Foreign Experts Affairs (SAFEA) Program, as well as the Natural Sciences and Engineering Research Council of Canada Discovery Grant Program and the Canada Research Chairs Program.

Acknowledgments: We would like to thank Qidong Hou for providing HPLC-RID.

Conflicts of Interest: The authors declare no conflict of interest.

\section{Nomenclature}

$\begin{array}{ll}A & \text { pre-exponential factor }\left(\mathrm{min}^{-1}\right) \\ \mathrm{k} & \text { reaction rate constant }\left(\mathrm{min}^{-1}\right) \\ \mathrm{E} & \text { activation energy }(\mathrm{kJ} / \mathrm{mol}) \\ \mathrm{R} & \left(\mathrm{kJ} \mathrm{mol}^{-1} \mathrm{~K}^{-1}\right) \\ \mathrm{T} & \text { temperature }(\mathrm{K}) \\ \mathrm{k}_{\mathrm{G}} & \text { glucose degradation rate constant }\left(\mathrm{min}^{-1}\right) \\ \mathrm{k}_{1} & \text { furfural formation rate constant }\left(\mathrm{min}^{-1}\right) \\ \mathrm{k}_{2} & \text { HMF formation rate constant }\left(\mathrm{min}^{-1}\right) \\ \mathrm{k}_{3} & \text { degradation rate constant for furfural }\left(\mathrm{min}^{-1}\right) \\ \mathrm{k}_{4} & \text { degradation rate constant for } \mathrm{HMF}\left(\mathrm{min}^{-1}\right) \\ \mathrm{C}_{\mathrm{GLU}} & \text { initial concentration of glucose }\left(\mathrm{mol} \mathrm{L}^{-1}\right) \\ \mathrm{C}_{\mathrm{HMF}} & \left.\text { initial concentration of HMF (mol L } \mathrm{L}^{-1}\right) \\ \mathrm{C}_{\mathrm{FUR}} & \left.\text { initial concentration of furfural (mol L } \mathrm{L}^{-1}\right) \\ \mathrm{E}_{\mathrm{a} 1} & \text { activation energy for furfural production }\left(\mathrm{kJ} \mathrm{mol}^{-1}\right) \\ \mathrm{E}_{\mathrm{a} 2} & \text { activation energy for HMF production }\left(\mathrm{kJ} \mathrm{mol}^{-1}\right) \\ \mathrm{E}_{\mathrm{a} 3} & \text { activation energy for furfural degradation }\left(\mathrm{kJ} \mathrm{mol}^{-1}\right) \\ \mathrm{E}_{\mathrm{a} 4} & \text { activation energy for HMF degradation }\left(\mathrm{kJ} \mathrm{mol}^{-1}\right) \\ \mathrm{E}_{\mathrm{a} 5} & \text { activation energy for glucose degradation }\left(\mathrm{kJ} \mathrm{mol}^{-1}\right)\end{array}$

\section{References}

1. Lakshmanan, V.I.; Roy, R.; Gorain, B. Renewable energy. In Innovations and Breakthroughs in the Gold and Silver Industries: Concepts, Applications and Future Trends; Springer: Berlin, Germany, 2019; ISBN 9783030325497.

2. Świątek, K.; Gaag, S.; Klier, A.; Kruse, A.; Sauer, J.; Steinbach, D. Acid hydrolysis of lignocellulosic biomass: Sugars and furfurals formation. Catalysts 2020, 10, 437. [CrossRef]

3. Ng, F.T.T.; Dalai, A.K. Catalysis for the production of sustainable fuels and chemicals. Catalysts 2020, 10, 388. [CrossRef]

4. Esteban, J.; Yustos, P.; Ladero, M. Catalytic processes from biomass-derived hexoses and pentoses: A recent literature overview. Catalysts 2018, 8, 637. [CrossRef]

5. Hao, W.; Zhao, G.; Tang, X.; Liu, S.; Lin, L.; Sun, Y.; Hu, L. Catalytic conversion of biomass-derived carbohydrates into fuels and chemicals via furanic aldehydes. RSC Adv. 2012, 2, 11184. [CrossRef]

6. Mariscal, R.; Maireles-Torres, P.; Ojeda, M.; Sádaba, I.; López Granados, M. Furfural: A renewable and versatile platform molecule for the synthesis of chemicals and fuels. Energy Environ. Sci. 2016, 9, 1144-1189. [CrossRef]

7. Kohli, K.; Prajapati, R.; Sharma, B.K. Bio-based chemicals from renewable biomass for integrated biorefineries. Energies 2019, 12, 233. [CrossRef]

8. Buntara, T.; Noel, S.; Phua, P.H.; Melián-Cabrera, I.; De Vries, J.G.; Heeres, H.J. Caprolactam from renewable resources: Catalytic conversion of 5-hydroxymethylfurfural into caprolactone. Angew. Chem. Int. Ed. 2011, 50, 7083-7087. [CrossRef]

9. Yang, H.; Yan, R.; Chen, H.; Lee, D.H.; Zheng, C. Characteristics of hemicellulose, cellulose and lignin pyrolysis. Fuel 2007, 86, 1781-1788. [CrossRef]

10. Lee, D.; Owens, V.N.; Boe, A.; Jeranyama, P. Composition of herbaceous biomass feedstocks. Cellulose 2007, 24, 16.

11. Dedes, G.; Karnaouri, A.; Topakas, E. Novel routes in transformation of lignocellulosic biomass to furan platform chemicals: From pretreatment to enzyme catalysis. Catalysts 2020, 10, 743. [CrossRef]

12. Chatterjee, C.; Pong, F.; Sen, A. Chemical conversion pathways for carbohydrates. Green Chem. 2015, 17, 40-71. [CrossRef]

13. Wang, Y.; Yang, X.; Zheng, H.; Li, X.; Zhu, Y.; Li, Y. Mechanistic insights on catalytic conversion fructose to furfural on beta zeolite via selective carbon-carbon bond cleavage. Mol. Catal. 2019, 463, 130-139. [CrossRef] 
14. Dutta, S.; De, S.; Saha, B. Advances in biomass transformation to 5-hydroxymethylfurfural and mechanistic aspects. Biomass Bioenergy 2013, 55, 355-369. [CrossRef]

15. Nikolla, E.; Román-Leshkov, Y.; Moliner, M.; Davis, M.E. “One-pot” synthesis of 5-(hydroxymethyl)furfural from carbohydrates using tin-beta zeolite. ACS Catal. 2011, 1, 408-410. [CrossRef]

16. Zhang, L.; Xi, G.; Chen, Z.; Jiang, D.; Yu, H.; Wang, X. Highly selective conversion of glucose into furfural over modified zeolites. Chem. Eng. J. 2017, 307, 868-876. [CrossRef]

17. Wang, K.; Ye, J.; Zhou, M.; Liu, P.; Liang, X.; Xu, J.; Jiang, J. Selective conversion of cellulose to levulinic acid and furfural in sulfolane/water solvent. Cellulose 2017. [CrossRef]

18. Yang, F.; Fu, J.; Mo, J.; Lu, X. Synergy of Lewis and Brønsted acids on catalytic hydrothermal decomposition of hexose to levulinic acid. Energy Fuels 2013, 27, 6973-6978. [CrossRef]

19. Gürbüz, E.I.; Gallo, J.M.R.; Alonso, D.M.; Wettstein, S.G.; Lim, W.Y.; Dumesic, J.A. Conversion of hemicellulose into furfural using solid acid catalysts in $\gamma$-valerolactone. Angew. Chem. Int. Ed. 2013, 52, 1270-1274. [CrossRef]

20. Jin, F.; Enomoto, H. Rapid and highly selective conversion of biomass into value-added products in hydrothermal conditions: Chemistry of acid/base-catalysed and oxidation reactions. Energy Environ. Sci. 2011, 4, 382-397. [CrossRef]

21. Wrigstedt, P.; Keskiväli, J.; Leskelä, M.; Repo, T. The role of salts and Brønsted acids in lewis acid-catalyzed aqueous-phase glucose dehydration to 5-hydroxymethylfurfural. ChemCatChem 2015, 7, 501-507. [CrossRef]

22. Mellmer, M.A.; Sener, C.; Gallo, J.M.R.; Luterbacher, J.S.; Alonso, D.M.; Dumesic, J.A. Solvent effects in acid-catalyzed biomass conversion reactions. Angew. Chem. Int. Ed. 2014, 53, 11872-11875. [CrossRef] [PubMed]

23. Walker, T.W.; Chew, A.K.; Li, H.; Demir, B.; Zhang, Z.C.; Huber, G.W.; Van Lehn, R.C.; Dumesic, J.A. Universal kinetic solvent effects in acid-catalyzed reactions of biomass-derived oxygenates. Energy Environ. Sci. 2018, 11, 617-628. [CrossRef]

24. Liu, C.; Wei, M.; Wang, F.; Wei, L.; Yin, X.; Jiang, J.; Wang, K. Effective and facile conversion of bamboo into platform chemicals over $\mathrm{SnCl} 4$ in a sulfolane/water solution. J. Energy Inst. 2020. [CrossRef]

25. Hu, B.; Lu, Q.; Jiang, X.; Dong, X.; Cui, M.; Dong, C.; Yang, Y. Pyrolysis mechanism of glucose and mannose: The formation of 5-hydroxymethyl furfural and furfural. J. Energy Chem. 2018, 27, 486-501. [CrossRef]

26. Asakawa, M.; Shrotri, A.; Kobayashi, H.; Fukuoka, A. Solvent basicity controlled deformylation for the formation of furfural from glucose and fructose. Green Chem. 2019, 21, 6146-6153. [CrossRef]

27. Cui, J.; Tan, J.; Deng, T.; Cui, X.; Zhu, Y.; Li, Y. Conversion of carbohydrates to furfural via selective cleavage of the carbon-carbon bond: The cooperative effects of zeolite and solvent. Green Chem. 2016, 18, 1619-1624. [CrossRef]

28. Wang, T.; Nolte, M.W.; Shanks, B.H. Catalytic dehydration of C6 carbohydrates for the production of hydroxymethylfurfural (HMF) as a versatile platform chemical. Green Chem. 2014, 16, 548-572. [CrossRef]

29. Wang, C.; Yang, G.; Zhang, X.; Shao, L.; Lyu, G.; Mao, J.; Liu, S.; Xu, F. A kinetic study on the hydrolysis of corncob residues to levulinic acid in the $\mathrm{FeCl}-\mathrm{NaCl}$ system. Cellulose 2019. [CrossRef]

30. Weiqi, W.; Shubin, W. Experimental and kinetic study of glucose conversion to levulinic acid catalyzed by synergy of Lewis and Brønsted acids. Chem. Eng. J. 2017, 307, 389-398. [CrossRef]

31. Atanda, L.; Konarova, M.; Ma, Q.; Mukundan, S.; Shrotri, A.; Beltramini, J. High yield conversion of cellulosic biomass into 5-hydroxymethylfurfural and a study of the reaction kinetics of cellulose to HMF conversion in a biphasic system. Catal. Sci. Technol. 2016, 6, 6257-6266. [CrossRef] 